\title{
Implementation of an efficient web-based movie ticket purchasing system in the context of Bangladesh
}

\author{
Gazi Zahirul Islam, Isrut Jahan Zinnia, Md. Fokhray Hossain, Md. Riazur Rahman, \\ Aman Ullah Juman, Al Nahian Bin Emran \\ Department of Computer Science and Engineering, Daffodil International University, Bangladesh
}

\begin{tabular}{l}
\hline Article Info \\
\hline Article history: \\
Received Nov 19, 2019 \\
Revised Mar 9, 2020 \\
Accepted Mar 26, 2020 \\
\hline Keywords: \\
CSS \\
Database \\
HTML \\
Java script \\
Module \\
Movie \\
PHP
\end{tabular}

\begin{abstract}
The 'Movie Ticket Purchase System' is a web-based application. In this application, people can purchase movie tickets from all movie theatres in Bangladesh. Before purchasing a ticket, people have to do registration or login. This website builds by PHP and JavaScript for back-end; HTML, CSS for front-end. All steps of the software development life cycle are addressed properly to develop and implement the software. This website has three panels: one for the Admin, one for the Theatre Assistant and another for the Customer/User. Admin can insert the theatres, and Theatre Assistant handled maximum manual works on the website like movie add, delete, stop running, screen adds, etc. This is the first website in Bangladesh where people can purchase tickets from multiple movie halls and the site is only dedicated to this purpose. The website is very user-friendly and attractive that can give comfort to the end users. Also, the theater owners that have no digital platform for selling tickets can be a member of our service and get the opportunity of using digital platform.
\end{abstract}

Copyright @ 2020 Institute of Advanced Engineering and Science. All rights reserved.

Corresponding Author:

Gazi Zahirul Islam,

Department of Computer Science and Engineering,

Daffodil International University,

Dhaka-1207, Bangladesh.

Email: zahir.cse@daffodilvarsity.edu.bd

\section{INTRODUCTION}

Now a days it is very common that peoples of all age groups are enjoying the cinema at the theater. It is our culture going to the theater for enjoying cinema along with the whole family. People want to spend their vacation, off-days, leisure time with their family friends and beloved persons by enjoying the cinema at the theater. No matter what ages they are. Not only the young generation people like to enjoy movies but also the people ages beyond 30 like to watch movies in the theaters. Our country is developing faster. People get engaged with their works more than before. But people also spend their leisure time watching movies in theater. As people get busy with their works, they do not want to waste their valuable time to purchase movie ticket standing in a line. But people in Bangladesh have no easy and flexible access for online ticket purchases so far. That's why we get the idea to implement a web-based movie ticket purchasing system. This is a dynamic website where people can find their desired movie list, which theater broadcasts which movies, ticket prices and other related information.

The users (i.e. both the end users and theater owners) can easily perceive the tremendous advantages of our system by visiting and using the website. It is the only website in Bangladesh that provides ticket purchasing facilities from multiple theaters at a time. Users can compare our website with other existing websites available in Bangladesh and realize the superiority of our site. This system would also be profitable for the theater owners as they can easily reach their customers by interactive GUI (Graphical User Interface) and can enrich their business. Prominent features of the online movie ticket system are listed below: 
a) Login and registration for users

b) View show time and theater name just by selecting your preferred movies

c) Now showing, coming soon, movie trailers etc.

d) Payment gateway and feedback

e) Dashboard for the admin and theater assistant

f) Add, delete and edit for movie theaters and movies

The paper is organized as follows. In Section 1, we introduce the work, and in Section 2, we discuss the related works that motivate us. Section 3 specifies and designs the system which contains Business Process Modeling, Use Case Modeling, and Logical Data Model. Section 4 titled 'Software Management' illustrates the Front-end and Back-end design. The system is tested and evaluated using several methods which are discussed in Section 5. Finally, Section 6 concludes the paper outling some promising features of this project.

\section{RELATED WORKS AND MOTIVATION}

Background study is necessary for any project to be implemented in a systematic and flexible way. We have analyzed and evaluated many similar projects for the background study such as [1-5]. This evaluation assists us in finding the limitations of those existing projects and helps us eliminating those limitations in our project.

\subsection{Existing works}

We examined many websites and found just only one website which is similar to our website in Bangladesh. This website belongs to a well-known IT service company of Bangladesh known as 'Shohoz' [6]. Shohoz is the most popular website in Bangladesh for purchasing different kinds of tickets e.g. theater, bus, train in online. Food delivery is also another renowned service provided by the 'Shohoz' app. Another renowned, popular and widely used app of the country named 'bKash' [7] (i.e. 30 million registered accounts) is also selling movie tickets through their mobile application. But the main limitation of 'Shohoz' and 'bKash' is that those apps are providing movie tickets only for one of the popular theaters of the country named 'Blockbuster Cinemas'. But other popular theaters such as 'Star Cineplex', 'Shyamoli Cinema' etc. are not included in those two apps. It is also noted that several well-known theaters are also providing online tickets through their respective websites [8-10]. By the way, there is no single website nor mobile app is developed so far in the country to provide movie tickets for multiple theaters.

We also went through several foreign websites [11-13] which provide online movie tickets. But those websites are not suitable for users for several reasons. Those websites are seeking redundant personal information while ticket booking and also the user interface is not user friendly. But user interface of our website is very user friendly and the site is also very flexible to use.

\subsection{Motivation}

In general, people of all walks of life in Bangladesh are fascinated to see the movies in a theater. The peoples have to buy movie tickets either through the online or physically going to the theater. As the world moving towards the 5G [14] and massive utilization of IoT [15], the BTRC (Bangladesh Telecommunication Regulatory Commission) [16] also has taken initiatives $[17,18]$ to roll out the $5 \mathrm{G}$ in the country by 2021. In this era of digital communication [19, 20]; it is unexpected buying the movie tickets going to the theaters physically. This is especially true, when Bangladesh enters into the $4 \mathrm{G}$ communications and Wi-Fi facility at the hand of mobile users [21] which in turn facilitates the users installing numerous apps. Thus, from the user's perspective, a user-friendly, flexible and up-to-date mobile app is very desirable at the moment. However, there is no unique app being developed so far that could meet the demand of the citizens. As our website and the whole system is well designed, fully completed and rigorously tested we could easily release a mobile app.

As mentioned above, only a few movie theaters have their own websites for selling tickets. As there is no single online platform for multiple theaters people have to browse multiple websites for findings their desire movie lists which is very time consuming. The busy peoples and the older citizens may find this very disappointing. Also, the theater owners that have no digital platform for selling tickets can be a member of our service and get the opportunity of using digital platform. To solve above problems, we motivate to implement this project. In our website, people can view the status of all movies of all theaters at a glance and can choose movie tickets from different theaters.

The viewers can search any movie related information by entering movie name and the website will show the theaters name and the time schedule for that movie. Users must have to login for purchasing or booking the tickets. After making the payment the system will send the digital receipt and ticket to the users 
email address. We carefully handled the transaction processing part by providing different payment methods such as 'bKash', 'Nagad' and debit/credit cards available in the country.

The design of our website is completely different from the existing websites. Our website is very polished, user-friendly, easy to understand the contents and very attractive to the customers. The website as well as the whole system is solely developed for movie ticket management. All theaters of Bangladesh could be included to our system. This is the site where people can find the latest movie details, coming soon movies and all the updates and details. This is the only website in Bangladesh where people can purchase movie tickets from any theaters easily and flexibly.

\section{SYSTEM DESIGN}

\subsection{Business process modeling}

Business Process Modeling is one kind of business process of an organization or enterprise where business workflow is represented graphically for prescribing potential improvements [22]. Graphical flowcharts, data-flow diagram, etc. are usually used for re-evaluating, promoting and sometimes for reworking the business process. Business process modeling is predominantly used for enhancing, analyzing, recovering and automating the current process for any organization [23].

In Figure 1, we have implemented a basic process model for the overall system where the actual business process is shown in a simple diagram. In this model, we can see there are three pathways for three types of users of the system: i). User (i.e. representing the movie viewers), ii). Admin (i.e. we the developer) and iii). Theater Assistant (i.e. representing theater owners). A user can login, select movie and book the show. The Admin has the actual power of controlling the whole system and possesses all access into the system. A Theater Assistant who is working for the theater owner can update the movie information and confirm the booking of tickets of their respective theater.

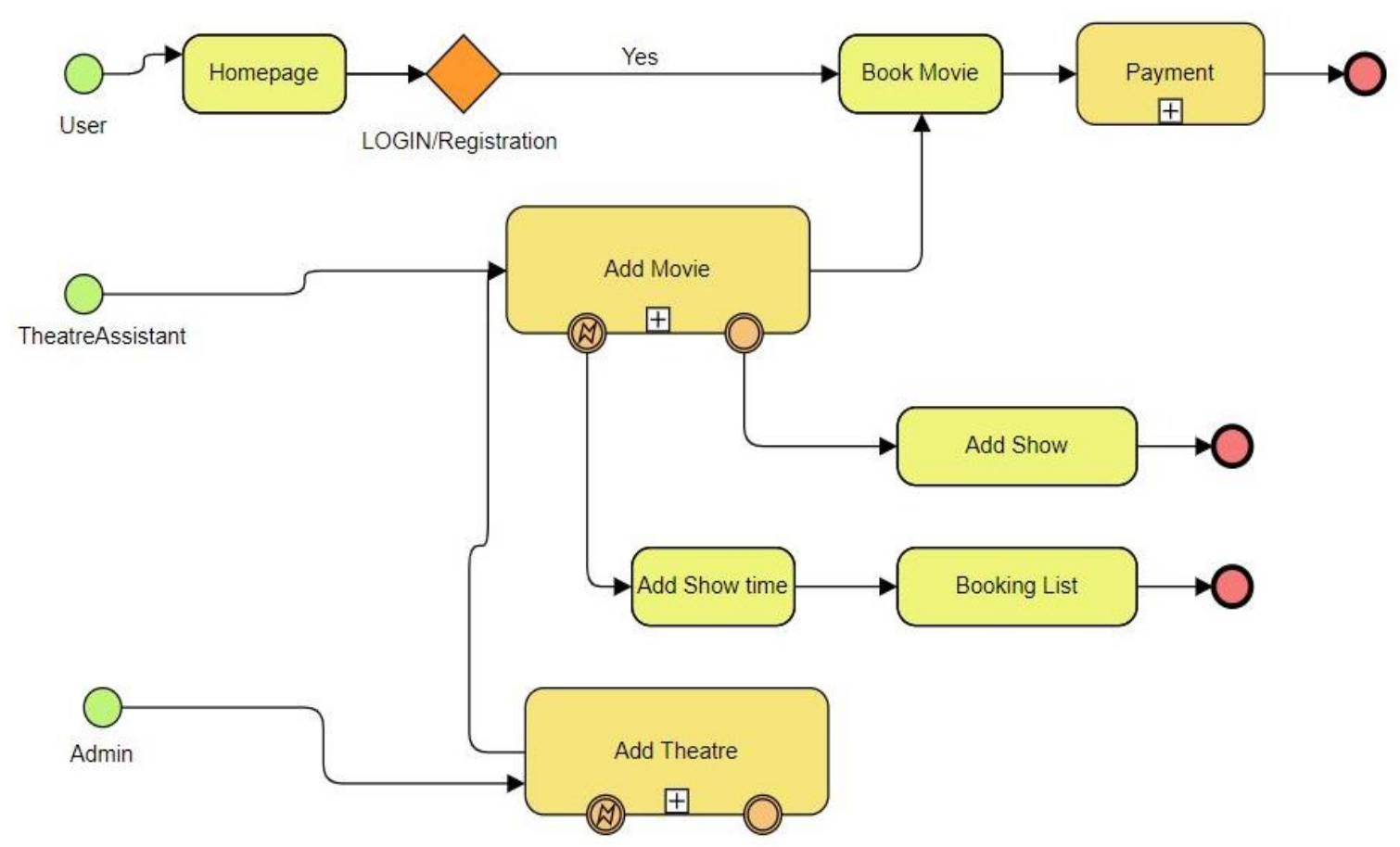

Figure 1. Business process model for the system

\subsection{Use case modeling}

The use case diagram is used to illustrate the dynamic behavior of a particular task [24]. The use case diagram describes the relationship between actors and the system to achieve an individual task [25]. The use case diagram of our system is shown in Figure 2. In this use case, there are three actors: admin, theater assistant and registered users whose main functions are listed in Table 1. All activities of a registered user are shown using a flowchart in Figure 3. 


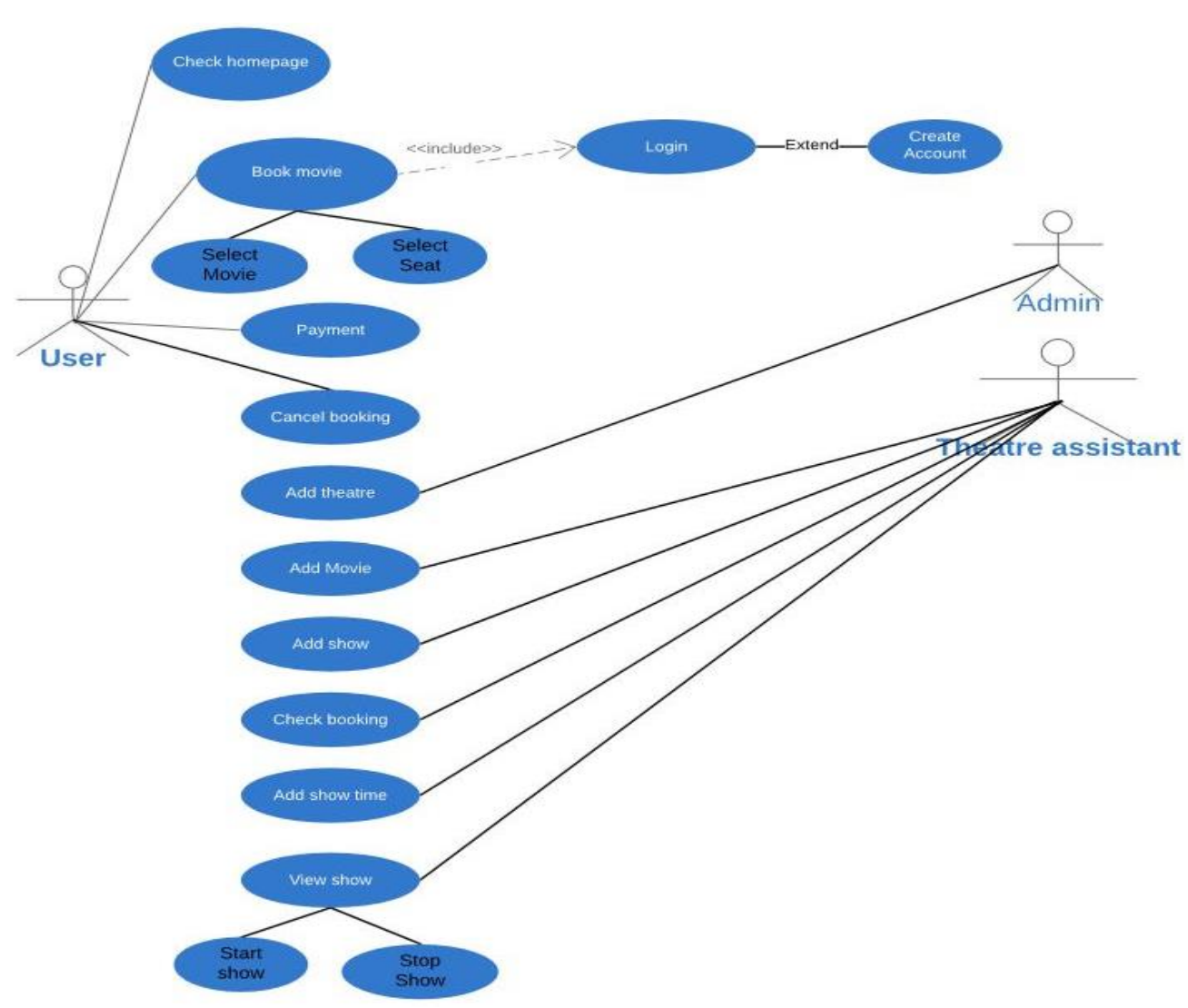

Figure 2. Use case diagram for the system

Table 1. Main functions of the three actors: admin, theater assistant and registered users

\begin{tabular}{llll}
\hline \multicolumn{1}{c}{ Functions of Admin } & Functions of Theater Assistant & Functions of Registered Users \\
\hline- Undertaking administrative tasks. & - Add, delete of movie name and & - User registration and login. \\
$-\quad$ Search for Movie hall. & related information. & - Search for movie hall, movie \\
$-\quad$ Handle the whole portal. & - Stop running shows. & show. \\
$-\quad$ Ensuring the venue. & - Check today's list. & - Get the latest update of the movie \\
$-\quad$ View the number of registered users & & and any offer. \\
& and analyze their activities. & & \\
$-\quad$ Add, edit, and delete each theater. & & \\
$-\quad \begin{array}{l}\text { Fetch all data on-site and control all } \\
\text { theaters' activities. }\end{array}$ & & \\
\hline
\end{tabular}

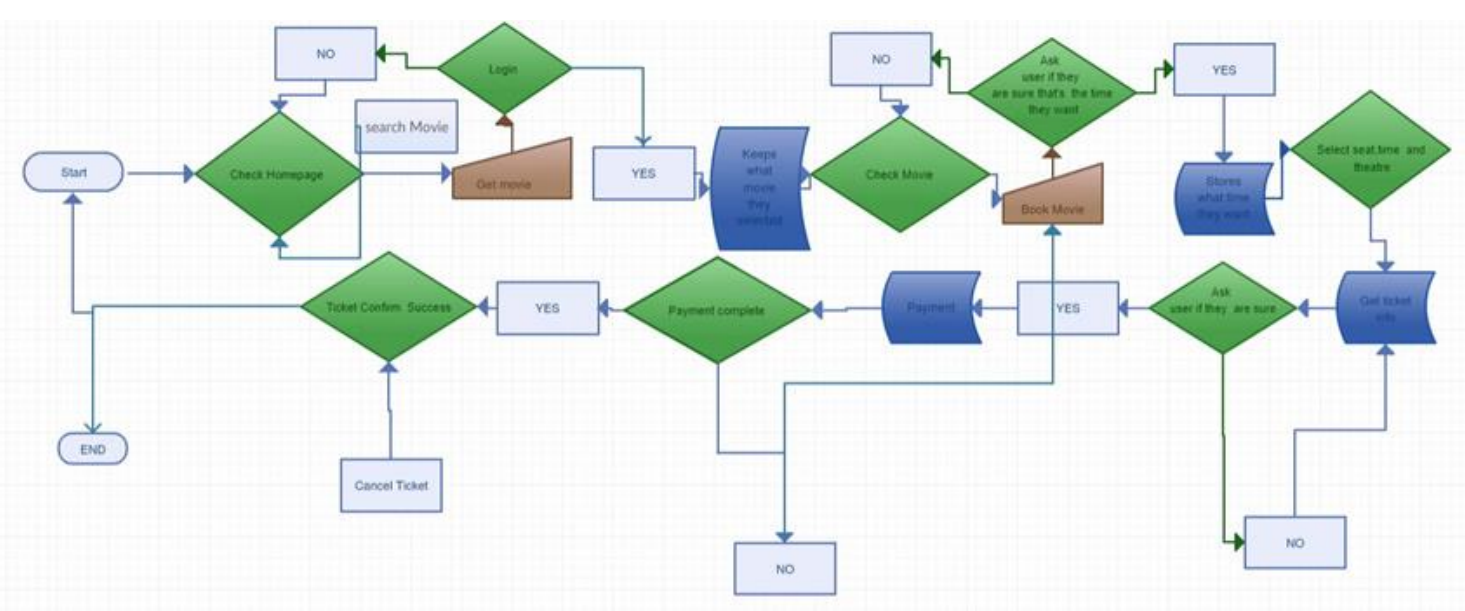

Figure 3. Activities of a registered users 


\subsection{Logical data model}

A logical data model is the representation of a particular database system for a specific problem domain [26]. Logical data model is one of physical or conceptual data model which is represented by using many relational tables and columns, object-oriented classes. The logical data model does not provide physical implementation details of the database system, it just gives a conceptual overview of data structure. The logical data model of our database is represented by the UML class diagram in Figure 4.

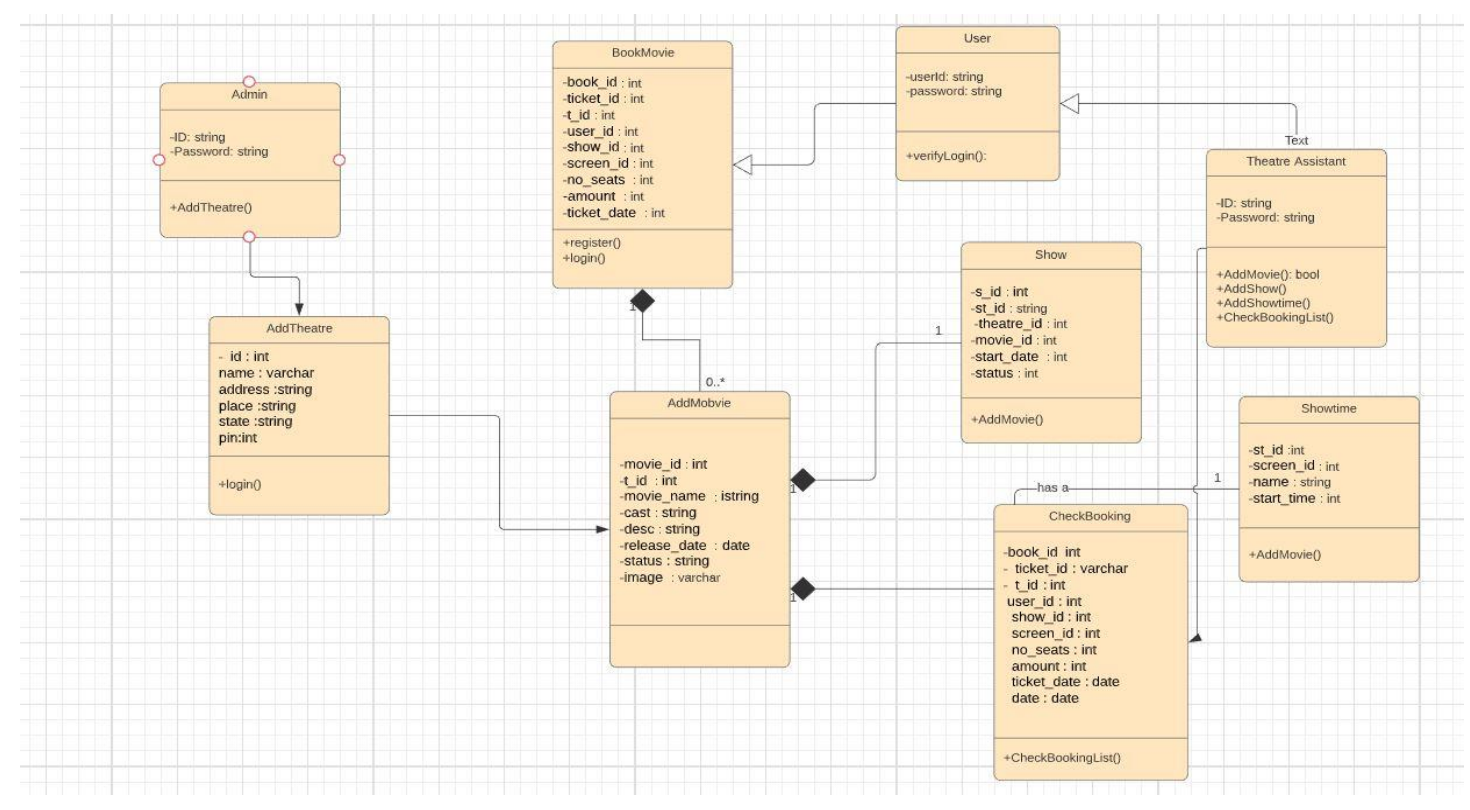

Figure 4. Class diagram of the database

\section{SOFTWARE MANAGEMENT}

In this section, we illustrate the front-end and back end design of the system in a concise and comprehensive way. A large class of software have been used for the front-end and back-end development. Section 4.1 describes the front-end implementation and section 4.2 describes the back-end implementation.

\subsection{Front-end design}

Attractive front-end design always impresses the viewers of the website. The front-end looks and its contents always have profound impacts to the site users. Our front-end design requires different web languages such as the HTML (Hypertext Markup Language), JavaScript, CSS (Cascading Style Sheet), etc. to develop the website.

The HTML is used here for creating and designing the documents for the web browser. The CSS and JavaScript assist the HTML developing a full-fledged impressive, customized and groomed website [27]. The HTML and CSS are the skeleton of any website and the websites become plain text or shapeless without the CSS. JavaScript is a dynamic scripting language that is highly suitable to add special effects on pages like rollover, roll out and many types of graphics. We also use the Bootstrap template for some front-end design to make the website more attractive and interactive. Bootstrap is a free and open-source CSS based framework [28] that helps to build our interface, because it contains HTML and CSS both in one file and it is easy to use.

"Interaction Design" and "User Experience Design" are the two key criteria of a web site to measure its popularity, acceptability, efficiency and productivity. There is a huge overlap between interaction design and user experience design. After all, user experience design is about shaping the experience of using a product, and a major part of that experience involves interaction between the user and the product. However, interaction and user experience do not reflect exactly the same phenomena. An interaction designer is focused on the moment when a user interacts with a product and their goal is to improve the interactive experience. For a user experience designer, the moment of interaction is just a part of the journey that a user goes through when they interact with a product. User experience design accounts for all user-facing aspects of a product or system such as the visual design, interaction design, information architecture, usability, 
content strategy, user research etc. Our website has an interactive GUI (Graphical User Interface) for the users where the customers can get information about the latest movies. We also get the data of user experience by surveying in the Dhaka City from a large population. The user experience is quite promising which is illustrated in Section 5.

The homepage of the website is shown in Figure 5. As the system is solely developed for movie ticket management, all movie related information is available at the web site. The user can book or buy ticket and make payment in an efficient, flexible and secured way. There is a navigation bar on top of the page which contains several modules namely, 'Home', 'Puchase Ticket', 'Login' 'Search' etc.

Several modules namely, 'Now Showing', 'Coming Soon' and 'Trailers' are added in the home page. Viewers can see the currently running movies in different theater on the 'Now Showing' module. The 'Coming Soon' module contains the upcoming movie list. The 'Trailers' is another key feature of our website where viewers can see the short movie clips. After a week or two 'Now Showing' items to be rescheduled by the theater assistant. By clicking on the movie icon or title of a movie viewers can see the movie details such as the release date, director name, etc.

There is a search bar on the website for searching any movie name, theater name or any other movie related information available in the system. People can know the date of which movie is running or coming to which theater easily. The people can watch the trailers without login or sign up. Then they can choose any movie or theater easily at their preferable price.

The main remarkable feature of this website is Book Movie/Ticket Purchase options. Unlike other websites available in the country, our website provides facilities for buying tickets from multiple theaters. To book a ticket, the people has to complete two steps as shown in Figure 6. At first, the user chooses a preferable theater for his selected movie i.e. Figure 6 (a). Then he books ticket by providing required information e.g. date, time, number of seats etc. i.e. Figure 6 (b). After booking the user can buy the ticket by making the payment as shown in Figure 7 and database table for the system as shown in Figure 8 . Then the admin confirms the ticket and would send the digital ticket to the user's email address. The payment gateway [29] is implemented by PHP (Hypertext Preprocessor) which is secure and very convenient to the users.

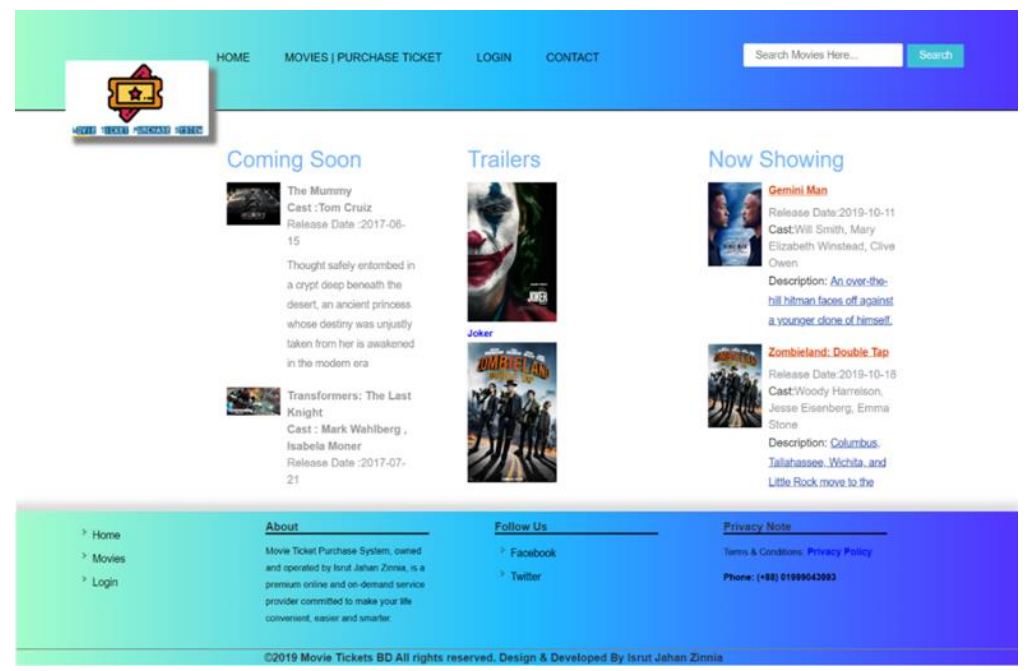

Figure 5. Home page of the website

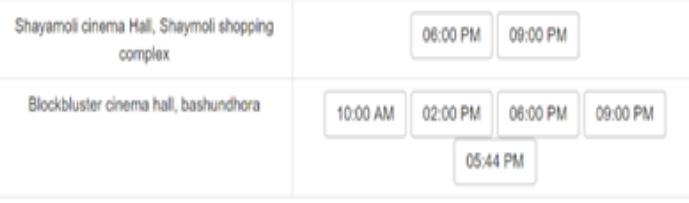

(a) Theater selection

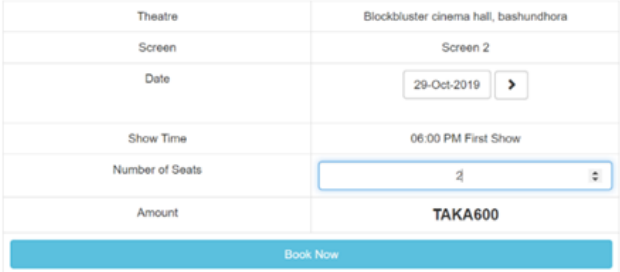

(b) Seat selection

Figure 6. Ticket booking procedure 


Name on Card
Isrut Jahan Zinnia
Card Number
E987654300872234
Expiration date
CVV
987
Make Payment

Figure 7. Payment gateway

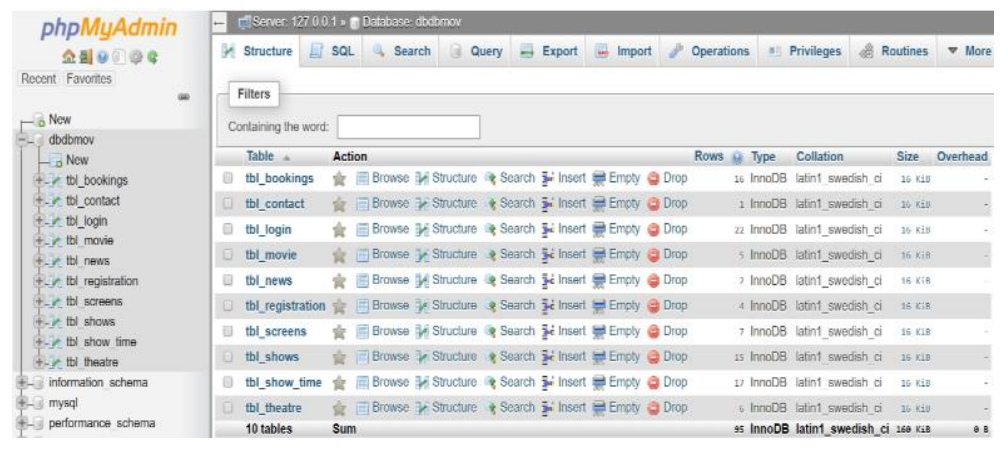

Figure 8. Database table for the system

\subsection{Back-end design}

The back-end has three parts: server, application, and database [30]. In our website, once the users enter all of their information such as their name, theater name, number of seats, etc., the web application stores the information in the database that was created previously on the server. We used following major components for the back-end implementation.

Sublime Text: This is a shareware cross-platform source code editor with a Python API (Application Programming Interface) [31]. It natively supports many programming languages and markup languages, and functions can be added by users with plugins, typically community-built and maintained under free-software licenses. We used this editor to provide support for the PHP, JavaScript, HTML, CSS, etc.

Server: We used XAMPP platform for the back-end solution. XAMPP stands for Cross-Platform $(\mathrm{X})$, Apache (A), MySQL (M), PHP (P) and Perl (P). It is a simple, lightweight Apache distribution for the developers to create a local web server for testing purposes [32]. The XAMPP platform makes out project very easy to implement.

Database: We used phpMyAdmin as a database tool for our website. This tool is easy to use and very user-friendly. phpMyAdmin is a free and open source administration tool for MySQL and MariaDB [33]. We extensively used server-side scripting language PHP [34] as it has many advanced features to support a wide range of databases efficiently.

\section{SYSTEM TESTING AND DATA ANALYSIS}

We used some methods to test and evaluate our websites after implementation. Initially, we tested our software using "Black Box Testing" method. Black box testing, also known as behavioral testing, is a software testing technique in which the internal structure/design/implementation of the item being tested is not known to the tester. We tested 15 different functions of the website using the black box testing and the result is shown in Table 2. The result shows that the system is perfect and can be utilized efficiently.

To perceive the users' acceptability or satisfaction of our implemented project, we conduct a survey on the movie viewers and theater owners/representatives. We collect feedbacks from 261 samples from the population of Dhaka City. Among the 261 samples, the number of viewers (end users) are 185 and the number of theater owners or their representatives are 76. Every sample test the website/system personally and rated as either (i) Excellent (ii) Very Good (iii) Satisfactory. Since the ordinary viewers and theater owners perspective is different to utilize the system, we use separate chart to represent their ratings. Figure 9 shows the viewers rating and Figure 10 shows the owners rating.

Examining Figure 9, it is noted that among 185 viewers, 88 rated as 'Excellent' i.e. 47.6\%, 80 rated as 'Very Good' i.e. 43.2\%, and 17 rated as 'Satifactory' i.e. 9.2\%. On the other hand, examining Figure 10, it is noted that among 76 owners, 59 rated as 'Excellent' i.e. $77.6 \%, 11$ rated as 'Very Good' i.e. $14.5 \%$ and 6 rated as 'Satifactory' i.e. $7.9 \%$. Undoubltedly, above statistics shows very high acceptability/satisfaction of the users which is undoubtedly very promising and optimistic. It is also noted that theater owners are more fascinated to this project than the viewers, because most of the movie owners in Bangladesh have not any digital platform yet to sell their tickets. 
Table 2. Black box testing of the system

\begin{tabular}{cccc}
\hline Id & Command & Outcome & Status \\
\hline Test case 1 & Registration request & Successful & pass \\
Test case 2 & Login request & Get access & pass \\
Test case 3 & Theater Categories & Categorized & pass \\
Test case 4 & Delete movies & Successful drop movies & pass \\
Test case 5 & logout & Logged out & pass \\
Test case 6 & Book ticket & Successful & pass \\
Test case 7 & Make payment & Successful transaction & pass \\
Test case 8 & Booking cancel & Successful drop booking & pass \\
Test case 9 & Insert theater & Successful & pass \\
Test case 10 & Add screen & Successful & pass \\
Test case 11 & Add showtimes & Successful & pass \\
Test case 12 & Search box & Successful & pass \\
Test case 13 & Add news & Successful & pass \\
Test case 14 & Add shows & Successful & pass \\
Test case 15 & Delete shows & Successful & pass \\
\hline
\end{tabular}

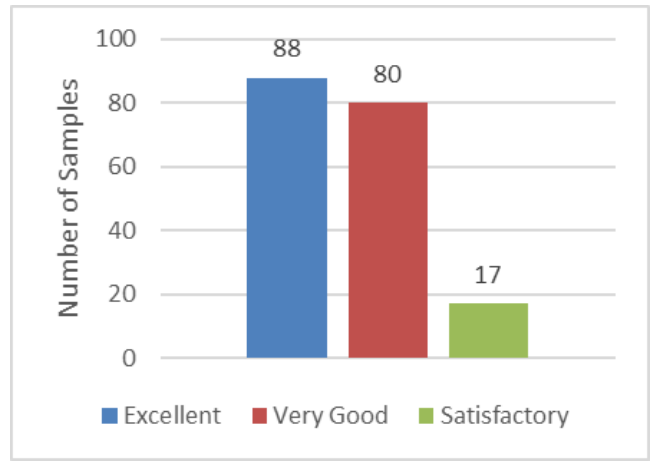

Figure 9. Viewers rating

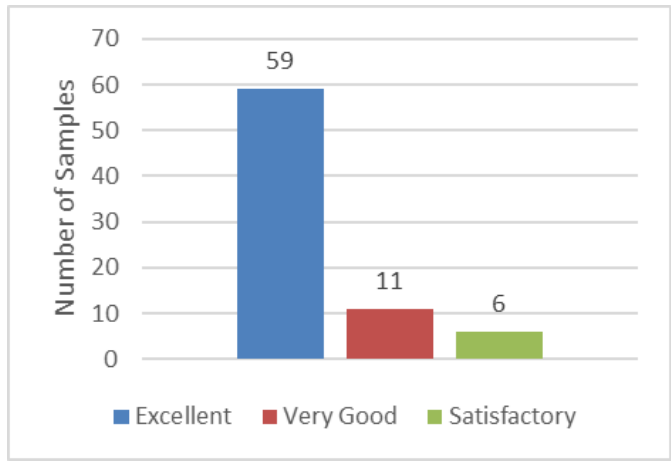

Figure 10. Owners rating

\section{CONCLUSION AND SCOPE}

The 'Movie Ticket Purchasing System' is a system where customers or users can easily purchase movie tickets from different movie theaters from a single website. The site is unique in the context of Bangladesh in the sense that it is only developed for movie ticket purchasing as well as it brings information from several theaters together in one site. There are no websites in Bangladesh that provides services for several theaters together.

Although, several mobile apps are selling movie tickets, those apps are predominantly used for other services. That's why, the users may feel discomfort while browsing those sites/apps and also face difficulties to buy the tickets. Also, the theater owners that have no digital platform for selling tickets can be a member of our service and get the opportunity of using digital platform. In the future, we hope to develop the apps for the 'Movie Ticket Purchasing System' both in the android and IOS platforms.

\section{REFERENCES}

[1] Rahul Rajouria, Vishal Yadav, Ruchika Mishra, Ruchika Mishra and Swati Jain, "Online Cinema Ticket Booking System," International Journal of Modern Engineering \& Management Research, vol. 3, no. 1, pp. 53-57, 2015.

[2] Archit Roy, Vinit Shahdeo and Rajesh Kaluri, "A Comparative Study in Online Movie Ticket Booking System," Research Journal of Engineering and Technology, vol. 10, no. 1, pp. 16-20, 2019.

[3] Prithviraj Y J, S Vaishnavi, Swathi R, Vemala Susmitha, "Online Movie Ticket Reservation”, International Journal for Technological Research in Engineering, vol. 3, no. 9, pp. 2320-2326, 2016.

[4] Jaganath M. and Raj Kumar R., "User Intention towards the Use of Movie Tickets Booking Applications," International Journal of Pure and Applied Mathematics, vol. 119, no. 12, pp. 51-57, 2018.

[5] Shivani Pal, Divya Thakur and Vijaya Shrivastaw, "Survey Paper on Online Movie Reservation," International Journal of Scientific Research and Review, vol. 07, no. 03, 2019.

[6] Shohoz.com, "Shohoz: Buy movie tickets instantly", November 08, 2015. [Online]. Available: https://www.shohoz.com/movies/. [Accessed: 11- Mar- 2020].

[7] bkash.com, "bKash-buy movie ticket", February 22, 2014. [Online]. Available: https://www.bkash.com/movie_ticket. [Accessed: 10- Mar- 2020].

[8] shyamolicinema.com, "Shyamoli Cinema", June 15, 2016. [Online]. Available: http://www.shyamolicinema.com/. [Accessed: 1- Mar- 2020]. 
[9] cineplexbd.com, “Star Cineplex”, June 24, 2015. [Online]. Available: https://www.cineplexbd.com/. [Accessed: 1- Mar- 2020].

[10] blockbusterbd.com, "Blockbuster Cinemas", May 05, 2020. [Online]. Available: https://blockbusterbd.com/. [Accessed: 1- Mar- 2020].

[11] in.bookmyshow.com, "Book my show", September 05, 2017. [Online]. Available: https://in.bookmyshow.com/mumbai. [Accessed: 25- Feb- 2020].

[12] paytm.com, "Paytm", July 11, 2019. [Online]. Available: https://paytm.com/movies/delhi-ncr [Accessed: 3- Mar2020].

[13] fandango.com, "FANDANGO", 2020. [Online]. Available: https://www.fandango.com/ [Accessed: 1- Mar- 2020].

[14] Gazi Zahirul Islam and Mohammod Abul Kashem, "An OFDMA-based Hybrid MAC Protocol for IEEE 802.11 ax,” Infocommunications Journal, vol. 11, no. 2, pp. 48-57, 2019.

[15] Teddy Surya Gunawan et. al., "Prototype Design of Smart Home System using Internet of Things," Indonesian Journal of Electrical Engineering and Computer Science (IJEECS), vol. 7, no. 1, pp. 107-115, 2017.

[16] btrc.gov.bd, "Bangladesh Telecommunication Regulatory Commission", January 13, 2019. [Online]. Available: http://www.btrc.gov.bd/telco/internet. [Accessed: 9- Mar- 2020].

[17] Al- Nahian Bin Emran, Aman Ullah Juman and Gazi Zahirul Islam, "Enhancement of Global Bandwidth of Internet Users Employing Internet Exchange Point Leveraging VPN Technology," 1st International Conference on Advances in Science, Engineering and Robotics Technology (ICASERT), pp. 48-52, 2019.

[18] Gazi Zahirul Islam, Aman Ullah Juman, Al Nahian Bin Emran, Md. Abbas Ali Khan, Md. Fokhray Hossain and Md. Tarek Habib, "Achieving Robust Global Bandwidth along with Bypassing Geo-restriction for Internet Users," Indonesian Journal of Electrical Engineering and Computer Science (IJEECS), vol. 18, no. 1, pp. 112-123, 2020.

[19] Gazi Zahirul Islam, Md. Ibrahim Khan and Md. Anas Boksh Mazady, "Developing a Model of E-governance for Urban and Rural Areas of Bangladesh" 11th International Conference on Computer and Information Technology (ICCIT), pp. 587-592, 2008.

[20] Md. Abbas Ali Khan, M. Raki Billah, Chandan Debnath, Sadekur Rahman, Md. Tarek Habib and Gazi Zahirul Islam "A Detailed Investigation of the Impact of Online Transportation on Bangladesh Economy," Indonesian Journal of Electrical Engineering and Computer Science (IJEECS), vol. 16, no. 1, pp. 420-428, 2019.

[21] Gazi Zahirul Islam and Mohammod Abul Kashem, "An OFDMA-based new MAC mechanism for IEEE 802.11ax," 5th International Conference on Networking, Systems and Security (NSysS), pp. 1-7, 2018.

[22] S. Tilley and H. J. Rosenblatt, "Systems Analysis and Design (Shelly Cashman Series)," $11^{\text {th }}$ Edition, Cengage Learning Inc, pp. 120-121, 2016.

[23] J. S. Valacich and J. F. George, "Modern Systems Analysis and Design," $8^{\text {th }}$ Edition, Pearson Education Limited, pp. 210-211, 2016.

[24] A. Dennis and B. H. Wixom, "Systems Analysis and Design: An Object-Oriented Approach with UML," $5^{\text {th }}$ Edition, Wiley, pp. 150, 2015.

[25] Edwin Mach, "Object Oriented Analysis \& Design Cookbook: Introduction to Practical System Modeling," Independently published, pp. 170-171, 2019.

[26] M. J. Hernandez, "Database Design for Mere Mortals: A Hands-On Guide to Relational Database Design," $3^{\text {rd }}$ Edition, Pearson Education, 2013.

[27] www.w3schools.com, "HTML and CSS learn from W3schools", January, 2019. [Online]. Available: https://www.w3schools.com/. [Accessed: 22- Dec- 2019].

[28] getbootstrap.com, "Bootstrap", November, 2019. [Online]. Available: https://getbootstrap.com/docs/4.3/gettingstarted/introduction/. [Accessed: 17- Oct- 2019].

[29] financesonline.com, "How to do payment gateway in PHP? | FinancesOnline", September, 2018. [Online]. Available: https://financesonline.com/how-to-do-payment-gateway-integration-in-php-java-and-c/. [Accessed: 27Nov- 2019].

[30] Robin Nixon, "Learning PHP, MySQL \& JavaScript", 5th Edition, O'Reilly Media, pp. 205, 223-224, 2018.

[31] sublimetext.com, "sublime text", February, 2019. [Online]. Available: https://www.sublimetext.com/. [Accessed: 2Mar- 2020].

[32] apachefriends.org, “Apache Friends”, June, 2019. [Online]. Available: https://www.apachefriends.org/index.html. [Accessed: 2- Mar- 2020].

[33] phpmyadmin.net, "phpMyAdmin", December, 2018 [Online]. Available: https://www.phpmyadmin.net/. [Accessed: 3- Mar- 2020].

[34] php.net, "PHP.”, November, 2018. [Online]. Available: https://www.php.net/. [Accessed: 4- Mar- 2020]. 